\title{
Doğuştan çarpık ayak - Ponseti yönteminin mantığı
}

\author{
Congenital clubfoot - the logic of Ponseti method
}

\author{
Emre Çullu, Ferit Tufan Özgezmez
}

Adnan Menderes Üniversitesi Tıp Fakültesi Hastanesi, Aydın

\begin{abstract}
Ponseti yönteminin başarılı olmasının en önemli nedeni; Ponseti'nin, hastalığın bileşenlerini en iyi biçimde tanımlamış olmasıdır. Bu deformitelerin hangi sıra ile düzeltilmesi gerektiğini incelikleriyle tarif eden Ponseti, pes ekinovarus tedavisinde bir devrim yapmış ve yüksek başarı oranlarına ulaşmıştır. Bu yöntemin temelinde; bağ dokularının, kemiklerin, eklemlerin, tendonların ve kıkırdak yapılarının manipülasyon ve alçılamalara kademeli olarak uyum göstermesi yatmaktadır. Elde edilen bu düzelmenin uzun süreli olması ve nüksler geliştiğinde görece daha kolay tedavi edilmesi, bu yöntemin en önemli avantajlarıdır. Başarı oranlarının yüksek olması da yöntemin yaygınlaşmasını sağlamış ve bu sayede birçok çocuk daha rahatlıkla sağlıklarına kavuşmuştur. Bu yazıda, Ponseti yönteminin temelleri ve uygulama prensipleri derlenmeye çalışılmıştır.
\end{abstract}

Anahtar sözcükler: doğumsal kusurlar; çarpık ayak; Ponseti yöntemi; talipes ekinovarus
The main reason of the success of Ponseti Method is his perfect description of the disease components. Presenting the correction of the deformities in detail and a suitable order, Ponseti has made a revolution, and his method achieved high success rates in the treatment of pes equinovarus. The basis of this method comprises a step by step adaptation of the ligaments, bones, joints, tendons, and cartilaginous structures to manipulations and castings. The most important advantages of this method are the permanence of improvements obtained and relatively easier treatment of the recurrences. High success rates provided a widespread practice of this method, and thereby a lot of children have easily returned to their health. This paper attempts a review of the basics and application principles of the Ponseti method.

Key words: congenital defects; clubfoot; Ponseti method; talipes equinovarus
G ünümüzde ortopedistlerin çoğu, pes ekinovarus (PEV) hastalığında ilk olarak yapılacak tedavilerin, konservatif tedaviler olması gerektiği konusunda hemfikirdirler. Eğer bir cerrahi müdahale yapılacaksa, en azından üçüncü aydan önce yapılmamalıdır. Her ne kadar, konservatif tedaviye başlama yaşı altı aydan küçük olanlarla, altı aydan büyük olanlar arasında tedavinin etkinliği açısından bir fark tespit edemediklerini belirten yazarlar olsa da; Ponseti, eklem kapsülleri, tendon ve bağların fibro-elastik özelliklerinin hayatın ilk günlerinde daha fazla olması nedeniyle, tedaviye mümkün olan en erken dönemde başlanması gerektiğini savunur. ${ }^{[1,2]}$

Ponseti metodu kullanılarak düzeltilen PEV'li ayaklarda, sadece bağların boylarını normale getirmekle yetinilmemekte, aynı zamanda hem tarsal kemiklerin birbirleri ile olan anormal ilişkisi hem de kemiklerin şekillerindeki anormallikler düzeltilebilmektedir. Bu düzelmenin temelinde, Wolff kanunu ${ }^{[3]}$ olarak bilinen kurallara paralel olarak, muhtemelen hızlı büyüme sürecindeki genç dokuların ve kemiklerin mekanik yüklenmelerdeki değişimlere uyum gösterme gücünün yüksek olması yatmaktadır. Üstelik Ponseti yönteminde, aşamalı ve nazik düzeltme ile birlikte uygulanan statik yüklenme, kısmen kemikleşmiş tarsal kemikleri saran ve çabucak yeniden şekillenebilen kıkırdak dokusunun büyümesine de engel olmaz. ${ }^{4]}$

Ponseti, kendi yöntemini geliştirmek için, öncelikle deformitenin doğru tanımlanması gerektiğini göz önüne almış, sonrasında ise nasıl bir sıra ile nereye ve ne yönde bir kuvvet uygulayarak düzeltme manevrasının yapılacağını anlamaya büyük önem vermiştir. Bu amaçla, normal ve PEV'li ayakları defalarca muayene edip, kemik ve eklemlerin hareketlerini hissedecek

- Illetişim adresi: Prof. Dr. Emre Çullu, Adnan Menderes Üniversitesi Tıp Fakültesi Hastanesi, Aydın

Tel: 0256 - 21420 40-1420 e-posta: ecullu@superonline.com ferittufan@gmail.com

- Geliș tarihi: 25 Mayıs 2015 Kabul tarihi: 25 Mayıs 2015 
şekilde parmaklarını eğitmiş, bu dokularda hassas disseksiyonlar yapmıştır. ${ }^{[5]}$

Talus kemiği, hafif bir ekinus dışında neredeyse normal ayaklardaki gibi mortisin içinde durur. Talus boynunda ise, normalden ortalama $20^{\circ}$ fazla, mediyale doğru bir açılanma mevcuttur. Ancak, ayağın talus altındaki kısmı talusa göre mediyale dönük ve deplase bir biçimdedir. Talus başı, navikulanın içe ve arkaya dönük olması nedeniyle, ayak sırtında lateral yüzde bir çıkıntı gibi görünür. Navikula, küboid, küneiformlar ve metatarslar, adduksiyonun şiddetine göre farklı derecelerde mediyale deplasedir. ${ }^{[5-8]}$

Kalkaneus, ciddi ekinusta ve ön tarafı direkt olarak talus başı altında durur. Topuk varusunun şiddetli olmasından bu pozisyon sorumludur. ${ }^{[5,8]}$

Küboid kemik, kalkaneusun ön yüzünde ve içe dönük olarak durur. ${ }^{[5,8]}$

Navikula, talusa göre ileri derecede mediyale dönüktür. Bu mediyal deplasman, navikulanın mediyal malleol ile çok yakın durmasına neden olur. ${ }^{[5,8]}$

Küneiformlar, navikula önünde içe ve aşağıya doğru deplasedir. ${ }^{[8]}$

Ponseti, farklı getasyonel yaşlardaki PEV'lerin disseksiyonunda, eklemlerin uyumlu olduğunu, eklemler arasında bir boşluk bulunmadığını, kapsül ve bağların histolojilerinin normal olduğunu, tendon insersiyonlarının normalde olmaları gereken yerlerde olduğunu gözlemlemiştir. Bunun yanında, bacak ve ayak kaslarının farklı çaplarda ve genellikle küçük olduğunu, navikulanın talusun aşırı derecede mediyalinde olduğunu görmüştür. Talus başının navikula ile örtünmeyen kısmının ayak sırtında bir çıkıntı oluşturduğunu ve üzerinin kıkırdakla kaplı olmadığını tespit etmiştir. ${ }^{[5]}$

Bu çalışmalar sonucunda Ponseti, PEV'in üç boyutlu bir deformite olduğunu; 1. metatarsın kavus deformitesinin ve ayak önünün, ayak arkasına göre pronasyondaki duruşunun öncelikli olarak düzeltilmesi gerektiğini; sonraki aşamalarda ise, ayak önü ayak arkasıyla aynı hizaya geldiğinde, adduksiyon, varus ve ekinus deformitelerinin birbiri ardına düzeltilmesi gerektiğini ortaya koymuştur. ${ }^{[6]}$ Diğer manipülatif tedavilerde, genelde kavus deformitesi düzeltilemediği için, başarısızlık olur. ${ }^{[7]}$

Ponseti, manipülasyonlarla kazanılan düzelmelerin korunması için ayağın sabitlenmesi gerektiğini; kısa olan sorunlu bağların bu sabitleme süresi boyunca, ayağın bu yeni duruşuna uyum göstererek boylarının uzadığını; hatta bir süre sonra yeni bir manipülasyon uygulanmasına izin verecek bir uzayabilme potansiyeli kazandığını görmüştür. ${ }^{[5,6,9]}$
Normal bir ayakta bağlar, kemikleri birbirine bağlayan viskoelastik yapılar olarak görev yapar ve eklemlerin hem stabil hem de esnek olmasına olanak sağlar. PEV'de, ayağın posterior ve mediyal bağları çok kalın ve gergin olur ve ayağı ekinusta, navikula ve kalkaneusu adduksiyon ve inversiyonda tutar. ${ }^{[5]}$

Bütün bağlar, mikroskobik olarak kıvrım diye adlandırılan, dalgalı kollajen demetlerinden oluşur. Bu kıvrımlar, bağlar gerildiğinde kaybolur. Eklemlerin alçı içerisinde sabitlenmesi, hem bağlarda hem de kemikbağ kavşağında sertliğin ve dayanıklıığın azalmasına neden olur. İmmobilizasyon, bağ içeriği üzerine yumuşatıcı bir etki de gösterir. ${ }^{[5,6]}$

Hem ayağın duruşunda, hem kemik, eklem ve bağların yapısında alçılamalarla elde edilen düzelmenin, alçı tedavisi sona erdiğinde de korunması gerektiğini gören Ponseti, ortez tedavisinin çok önemli bir idame tedavi olduğunu düşünmüştür. ${ }^{[6,8]}$

PEV'li bir ayağın temel bir bileşeni olan kavusun ana nedeni, ayak önünün ayak arkasına göre daha pronasyonda olmasıdır. Birinci metatarsın, beşinci metatarsa göre daha fazla fleksiyonda olması da buna katkı verir. PEV'de öncelikli olarak düzeltilmesi gereken patoloji budur. Kalkaneus ciddi şekilde ekinusta durmakla birlikte, kalkaneusun ön kısmı talus başı altında sıkışmış bir pozisyondadır. Bu pozisyon, kalkaneusun varusta olmasının ana nedenidir. PEV deformitesinin varus bileşeni, ayağın, özellikle de ayak önünün supinasyondaymış gibi görünmesine neden olur. Ponseti yöntemi ile tanışmamış ortopedistler de, yanlış olarak, bu deformiteyi düzeltmek için ayak önüne pronasyon yapma ihtiyacı hissederler. Ne yazık ki, ayağın deformiteyi düzeltme amacıyla pronasyona getirilmesi, ayak önünün ayak arkasına göre daha fazla pronasyonda olmasına ve kavusun artmasına neden olur. Oysa, her ne kadar ayak arkası supinasyonda ve inversiyonda duruyor olsa da, ayak önü ayak arkasına göre pronasyonda olduğu için, redüksiyonun ilk aşaması ayak önünü supinasyona getirmek olmalıdır. Bu manevra ile; pronasyon twist önlenmiş, kavus deformitesi düzeltilmiş ve ayak önü ayak arkasıyla aynı hizaya getirilmiş olur. Eğer ilk düzeltme manevrası ayak önünün supinasyona getirilmesi olmazsa, kavus deformitesi artar ve kalkaneus, talus altında adduksiyonda kilitlenmiş olur. ${ }^{[2,8,9]}$

\section{PONSETI TEKNIĞi, UYGULAMA DETAYLARI VE DIKKAT EDILECEK NOKTALAR}

Ponseti'nin tedavi yönteminde, düzeltme manevraları, alçılamalar, gerektiğinde aşilotomi, ortez ve nüksler geliştiğinde aşiloplasti ve tibialis anterior tendon transferi gibi nispeten daha minör operasyonlar yapılır. 
Bebeğin ailesiyle, bu minör operasyonların ve tedavi planının, öngörülen tedavi süresinin, tedavinin ortezleme aşmasında ebeveynlere de bazı görevler düşeceğinin henüz tedaviye başlamadan konuşulması, bu uzun tedaviye ailenin kendisini hazırlamasına yardımcı olabilir.

Düzeltici manevra ve alçılamalara, mümkün olan en erken dönemde başlanmalı ve zaman kaybedilmemelidir. Geçen zaman içinde ayaktaki esneklik azalacağından, tedavi süresi uzayabilir.

Redüksiyon manevrasını uygularken herhangi bir anestezi gereksinimi olmaz. ${ }^{[8]}$ Yapılacak manevra, bebeğe zarar verecek şiddette olmamalı, işlem yapılırken bebek rahat olmalı ve beslenmesine izin verilmelidir. ${ }^{[5,9]}$

Önceki alçı evde değil, hastanede çıkarılmalı ve alçı çıkar çıkmaz, vakit kaybetmeden gerekli manipülasyonlar yapılarak yeni alçı uygulanmalıdır. Alçı evde çıkarılacaksa, alçısız kalınan süre uzatılmamalıdır. Çünkü, alçının bir gece önce evde çıkarılması, tedavi süresini ve gereken alçı sayısını yaklaşık iki katına çıkarır. ${ }^{[10]}$

Alçı değişimleri beş veya yedi gün arayla yapılmalı, eğer aşilotomi yapıldıysa, son alçı üç hafta tutulmalıdır. ${ }^{[2,5,9]}$ Son dönemlerde hızlandırılmış tedaviler uygulanmış, alçılar arasındaki sürenin haftada iki alçı olacak şekilde uygulanmasının da başarılı olabileceği görülmüştür. [11] Morcuende ve arkadaşları, üç-dört günde bir alçı değişimi yapıldığında hastaların rahatsız olduklarını, parmaklarda ödem oluştuğunu ve ayağın süperiorunda ve mediyalinde şişlik geliştiğini gözlemlemişler ve uygun aralığın beş gün olması gerektiğine karar vermişlerdir. ${ }^{[12]}$ Bunun yanında Elgohary, haftada iki kez alçı değişiminin yapıldığı hızlandırılmış tedavilerin, geleneksel yönteme göre yapılması gereken alçı sayısını hafif bir miktar yükseltse de, tedavi süresini belirgin şekilde kısalttığını gözlemlemiştir. ${ }^{[11]}$

Harnett, hızlandırılmış tedavi sonuçlarını yayımlayan Morcuende'ninkinden daha iyi tasarlanmış bir çalışma ile (ileriye dönük randomize kontrollü deneysel çalışma), haftada üç alçı değişimi yapılırsa tedavi süresinin yaklaşık 3,3 kat hızlı olduğunu, gereken alçı sayısında anlamlı bir fark olmadığını göstermiştir. Üstelik hızlandırılmış tedavilerde Morcuende ayakta şişlik geliştiğinden söz etmesine karşın, Harnett böyle bir sorunla karşılaşmadıklarını belirtmektedir. ${ }^{[13]}$

Xu, kendi çalışmasında, haftada iki defa alçı değişimi uygulandığında, toplamda uygulanması gereken alçı sayısında anlamlı bir fark olmadığını, dolayısıyla tedavi süresinin de yarıya indiğini belirtmektedir. Xu da, kendi serisinde, ayakta ödem gelişmediğini belirtmektedir. ${ }^{[14]}$

Morcuende ve arkadaşları, manipülasyon ve bantlama yönteminde (Fransız metodunda) statik yüklenme elde edilemediği için, tedavinin Ponseti yöntemine göre daha geç sonlandığını düşünmektedirler. Ancak, alçı yapılarak elde edilen bu statik yüklenmenin kemik ve bağ dokularına nasıl etki ettiğini, hücresel metabolik aktivitelerini nasıl değiştirdiğini ve büyüme şekillerini nasıl bu kadar çarpıcı olarak iyileştirdiğini daha iyi açıklayacak çalışmalara gerek olduğunu belirtmektedirler. ${ }^{[12]}$

Alçı çıkarılırken, bebeğin cildine zarar verme olasılığı olan yöntemlerden ve alçı motoru kullanmaktan kaçınılmalıdır. Ponseti, alçının yaklaşık 20 dakika suda tutulmasını, daha sonra ıslak bezlerle sarılmasını ve böylece yumuşayan alçının alçı bıçağı kullanılarak kesilmesini önermektedir. ${ }^{[5,9]}$

Önceki alçı çıkartılırken yeni alçı için hazırıklar yapılmış olmalı, gerekli malzemeler ve bir yardımcı personel hazır bulundurulmalıdır. Çünkü, alçı açıldıktan sonra fazla vakit kaybedilmemelidir. Bekleme süresi arttıkça, kazanılmış olan düzelme kaybedilebilir.

Kendi uygulamamızda, yaklaşık 1,5 aylık alçılama süresini bebeğin banyo yapmadan geçirmemesi amacıyla, şöyle bir yol izlemekteyiz: Alçısız geçen süre iki saati aşmayacaksa, aile evde alçıyı sirkeli suyla ıslatılmış bezlerle yumuşattıktan sonra, motor ile kesme işlemi uygulamadan alçıyı açar ve bebeğe banyosunu yaptırır. Alçısı çıkarılmış ve banyosu yaptırılmış olan bebek hastaneye zaman kaybedilmeden getirilir ve yeni alçı yapılır.

Alçı iki aşamada yapılır: Öncelikle, dize kadar bir alçı yapılır ve sertleşmesi beklenir. Diz altına kadar olan alçı sertleştikten sonra tibia hafif eksternal rotasyonda tutularak, dize de $90^{\circ}$ fleksiyon verilerek alçı diz üstüne doğru uzatılır. Bu manevra ile internal tibial torsiyon düzeltilecektir. Eğer alçı kasığa kadar yapılmaz ve diz altında kalırsa, talus ve tibia rotasyondan korunamaz, kazanılmış olan düzelme kaybedilir. Vurukların gelişmesini önlemek amacıyla, alçı altına ince bir kat alçı altı pamuğu sarmak gerekir. Alçı iki aşamada yapılacağı için pamuk da iki aşamada sarılmalıdır. ${ }^{[2,5,8]}$

Pamuk sarma ve alçılama işlemine başlamadan önce, ayak redüksiyonu korunacak şekilde bir yardımcıya tutturulur ve pamuk sarılır. Pamuk sarma işlemi bitikten sonra, alçı sarılması işlemine geçilir.

Alçı da, yine yardımcının parmakları üzerinden sarılır. Böylelikle, bebeğin parmakları için yeterli boşluk bırakılmış olur. Alçıya, ayak parmakları çevresine üç ya da dört tur alçı sararak başlanır. Daha sonra alçı, bacağın proksimaline doğru uzatılır. Alçı sarılırken geniş ve düzgün sarılmalı, topuk üzerinde biraz gerginleştirilmelidir. ${ }^{[9]}$

Sarma işlemi bitince, alçının sertleşmesi esnasında, şekillendirme işlemi başlar. Şekillendirme işlemi nazik 
bir şekilde yapılmalıdır. Alçının hiçbir yerine devamlı bası uygulanmamalıdır. Şekil verme işlemi dinamik bir işlem olmalıdır. Alçının topuğa, talus başı üzerine ve mediyal longitudinal arka iyice oturtulmuş olması gerekir. Alçı topuğa oturtulurken kalkaneusa kesinlikle herhangi bir kuvvet uygulanmamalı, kalkaneus manipüle edilmemelidir. Alçı talusa oturtulurken sabit basınç uygulanmamalı, tekrarlayan şekilde basma ve gevşeme yapılmalıdır. Örneğin, PEV'li bir sağ ayağa alçı yapılırken, ayak parmakları ve uyluk bir yardımcı tarafindan redükte pozisyonda tutulur. Hekimin sol el işaret parmağı, kalkaneus üzerine hiçbir manipülasyon ve baskı yapmadan alçıya şekil verirken, yine sol elin başparmağı alçıyı talus başı üzerine oturtmalıdır. Düztabanlık ve kayık ayak (rocker-bottom) deformitesinin gelişmesine engel olmak için, sağ elin işaret parmağı mediyal longitudinal arkı desteklemeli ve alçııı mediyal longitudinal arka oturtmalıdır. ${ }^{[9]}$

Dize kadar olan alçı yapıldıktan ve uygun şekilde sertleştikten sonra, diz $90^{\circ}$ fleksiyonda olacak şekilde alçının diz üstü kısmı yapılır. Cilt tahrişinin önlenmesi için, alçı altına kalınca pamuk sarılır. Alçı sarılırken, alçının popliteada birikip, çıkarılmasını zorlaştıracak bir şekil almasına engel olmak gerekir. Bunun için, diz önünde fazladan birkaç kat alçı oluşturmak, hem diz seviyesinde alçının sağlamlaşmasına yardımcı olur hem de popliteal bölgede kalın bir katman oluşmasını önler. ${ }^{[5,9]}$

Alçı tamamen bittikten sonra, alçının parmakların altındaki kısmı bırakılarak, dorsal kısmı bütün parmaklar görülecek şekilde, metatarsofalengeal eklem seviyesine kadar açılır. ${ }^{[9]}$ Parmakların dolaşımı tek tek kontrol edilir. Alçı bittiğinde, parmak dolaşımlarının iyi, bebeğin huzurlu, ağrısız ve rahat olması beklenir. Hastanın eve yollanmadan önce bir süre -yaklaşık yarım saat- hastanede tutulması, hekime gelişebilecek bir alçı komplikasyonunu erken fark etme fırsatı verebilir.

Alçı ile immobilizasyon sağlandığında, gergin olan mediyal ve posterior yapılar esneme eğilimi gösterir. Esnemiş ve uzamış olan bu bağlar, bir sonraki alçıda tekrar gerdirilirken biraz daha uzamış olur ve alçı içinde immobilize edilirken yine gevşeme eğilimi gösterir. Böylelikle, her alçı yapıldığında bağların boylarında bir miktar uzama elde edilmiş olur. ${ }^{[5]}$

Ponseti, manipülasyon ve alçılamaların tecrübeli hekimlerce uygulanması ve herhangi bir modifikasyon yapılmaması gerektiğini söyler. ${ }^{[2]}$ Ponseti yönteminde modifikasyonlar yapılması, başarısızlığa neden olabilir. ${ }^{[15]}$ Ponseti, kendi tedavi yönteminin kolay öğrenilebilir olduğunu, meraklı ve ilgili bir ortopedi asistanının, iki veya üç PEV deformitesini başarıyla düzeltmesinin, yöntemi uygulamada artık yeterli olduğu anlamına geldiğini belirtir. ${ }^{[2]}$
Alçılama sürecinde düzeltilmesi hedeflenen deformiteler ve manevra şekli, ilk alçı, idame alçılar ve son alçıda farklılıklar gösterir.

\section{ILK ALÇILAMA}

Illk alçıda düzeltilmesi hedeflenen patoloji, ayak önünün ayak arkasına göre olan pronasyon deformitesi, yani mediyal longitudinal arkın kavus deformitesidir. Bunu düzeltebilmek için, talus başı stabilize edilerek ve özellikle 1. metatarsın fleksiyon deformitesi düzeltilerek, bütün ayak önü supinasyona getirilir. Ayak önü supinasyona getirildikçe, ayağın kavus deformitesi de düzelir. ${ }^{[2,5,9]}$

Bu aşamada, talus başının doğru tespit edilmesi çok kritiktir. Bir el (sağ ayak için hekimin sağ eli) redüksiyonu yapamaya hazır bir şeklide ayak önünü tutuyorken, diğer el işaret parmağı ve başparmak ile mediyal ve lateral malleol tespit edilir. İşaret parmağı mediyal malleole, başparmak lateral malleole konmalıdır. Daha sonra işaret parmağı ve başparmak öne doğru kaydırılarak, mediyal tarafta navikulanın neredeyse mediyal malleole bitişik olacak şekilde yer değiştirdiği ve lateral tarafta ise lateral malleolün önünde, bir çıkıntı şeklinde, talus başı hissedilir. Hissedilen bu çıkıntının gerçekten talus başı olduğunu anlamak için, başparmak talus başını tespit ederken, redüksiyonu yapmak için hazır bulundurulan el, ayak önünü supinasyona alıp laterale kaydırır. Bu esnada, talus başı önünde naviküler kemiğin az miktarda da olsa hereket ettiği, talus başı altında ise kalkaneusun laterale doğru kaydığı hissedilmelidir. Bu hareket uygulanırken, navikulanın hareketinin kısıtlı ve mediyal malleole uzaklığının az olması, deformitenin ciddi olduğuna işaret eder. ${ }^{[2,9]}$

Talus doğru olarak tespit edildikten sonra, aynı elin başparmağı talus üzerine, işaret parmağı ise lateral malleolün posterioruna konmalıdır. Bu hareket, ayağa manipülasyon yapılırken lateral malleolü posteriora doğru çekecek olan posterior kalkaneofibular bağın gerilmesini önler. Posterior kalkaneofibular bağın gerilerek lateral malleolün posteriora iyatrojenik olarak deplase olmasını önlemek için, abduksiyon hareketi yaptırılırken ayağın ekinusta ve hafif supinasyonda olması gerekir. Böylelikle, mediyal tarsal bağlar gerilir, kalkaneusun talus altından abduksiyona gelmesine ve topuk varusunun düzelmesine izin verir. ${ }^{[2]}$

Doğru tutuş sağlandıktan sonra, manipülasyona başlanabilir. Sol elin işaret parmağı lateral malleolün posteriorunda, başparmağı ise talus başı üzerinde talusu tespit ederken, sağ el ile ön ayak supinasyona doğru, çocukta rahatsızlık uyandırmadan, mümkün olduğu kadar abduksiyona getirilir. Bu pozisyonda iken, hafif bir basınçla yaklaşık bir dakika tutulur ve sonra 
ayak serbest bırakılır. Birkaç defa bu işlem yapıldıktan sonra, deformite esnemiş olur ve bu düzeltmeyi korumak için alçı uygulanır. ${ }^{[2,5,9]}$

Düzeltme kuvvetini karşılamak için, başparmakla talus başına kuvvet uygulamak önemlidir. Eğer bu kuvvet yanlışlıkla daha inferiordaki kalkaneusa uygulanırsa, topuk varusu düzelmez. ${ }^{[2]}$

İlk alçı bittiğinde, alçı dikkatli bir şekilde kontrol edilmelidir. Ayağın ekinusta olduğu ve ayak önünün ise tamamen supinasyonda durduğu gözlenmelidir. ${ }^{[2]}$ Aksi durumda, alçının başarısız olduğu kabul edilip yenisi yapılmalıdır. illk alçıda ayak bileği ekinusuna düzeltme uygulanmaz. Özelikle birinci alçıda olmak üzere, redüksiyonun hiçbir aşamasında ayak önü pronasyona getirilmemelidir. ${ }^{[2,5,9]}$

Bu alçılama ile adduktus ve kavus deformitesi düzelmiş olmalıdır; eğer düzelme olmuşsa, sonraki aşamalara geçilir.

\section{iKINCi, ÜÇÜNCÜ VE DÖRDÜNCÜ ALÇILAMALAR (IDAME ALÇILAR)}

$\mathrm{Bu}$ alçılamalarda düzeltilmesi hedeflenen patoloji, ayağın adduktus ve varus deformitesidir. ${ }^{[5,9]}$ Bunu yapabilmek için, eski alçı çıkarıldıktan sonra aynı düzeltme manevrası uygulanarak, yeniden alçılamalar yapılır. Her alçı ile biraz daha düzelme elde edilmiş olur.

Manevra uygulanırken, ayak bileği ekinus deformitesi dolaylı olarak, yani kavus ve adduktus düzeldikçe talusun altından kurtulup laterale kayan kalkaneusun, aynı zamanda dorsifleksiyon yapmış olmasıyla, bir miktar düzelir. Varus ve adduktus deformiteleri düzelmeden, kalkaneus talusun altından laterale yani olması gereken yere gelmeden, ekinus deformitesi düzeltilmeye çalışılmamalıdır. ${ }^{[8]}$

$\mathrm{Bu}$ aşamanın yeterli düzeyde yapıldığını anlamak için, navikulanın konumu değerlendirilir. Mediyal malleol ve naviküler tüberozite arasındaki mesafe 1,5-2 $\mathrm{cm}$ olmalı ve navikula talus başının ön yüzeyini örtmelidir. Alçılama sonunda, kavus, adduktus ve varus deformitesinin tamamen düzeldiği görülmelidir. Yeterli abduksiyonun elde edilebildiğinin kanıtı; abduksiyon yapıldığında kalkaneus ön çıkıntısının talus altında palpe edilebilmesi ve tibianın frontal düzlemine göre yaklaşık $60^{\circ}$ abduksiyonun gözlenmesidir. Eğer bu düzelmeler sağlanamamışsa, aynı mantıkla bir veya birkaç alçı daha yapılmalıdır. ${ }^{[2]}$

Ancak ilk yapılan iki veya üç alçıda hiçbir düzelme elde edilememişse, olgunun kompleks bir durumu olduğu kabul edilerek, hastanın daha tecrübeli merkezlere yönlendirilmesi gerektiği de unutulmamalı$\operatorname{dir}{ }^{[2]}$
Kavus, adduktus ve varus deformitelerinin tamamen düzeldiği tespit edildiğinde, ayak bileği ekinus deformitesinin durumu değerlendirilmelidir. Diğer deformiteler düzeltilirken, ekinus deformitesi de bir miktar düzelmiş olur. Ekinus deformitesi tam olarak düzelmeyen ayaklara, eğer ayaklar yumuşaksa, ek birkaç alçı daha yapılabilir. Ancak, yeterli düzelme sağlanamıyorsa, zaman kaybetmeden Aşil tenotomisi yapılmalıdır. ${ }^{[2,9]}$

Çünkü alçı tedavisini gereksiz yere uzatmak, bacakları daha uzun süre immobilize etmeye neden olarak, ayakta sertliğe neden olabilir. ${ }^{[5]}$

\section{EKINUSUN DÜZELTILMESi VE BEŞiNCi ALÇı (SON ALÇI)}

Ekinusun düzeltilmesi, topuk varusunun düzelmesinden sonra yapılır. Topuk ya nötralde ya da biraz valgusta ise, ekinus düzeltmesine başlanabilir. ${ }^{[8]}$ Eğer topuk varusu ve ayak supinasyonu düzeltilmeden ekinus düzeltilmeye çalışılırsa, kayık ayak (rocker-bottom) deformitesi ortaya çıkar. ${ }^{[2]}$

Aşil gerginliği nedeniyle, ekinusun düzelmesi zor olabilir. İki ya da üç alçı yetmezse, beklenmeden tenotomi yapılmalıdır. ${ }^{[2]}$

Tenotomi gereksinimi olan hastalarda tenotomi yapıldıktan sonra, ayak bileği $20^{\circ}$ dorsifleksiyonda, ayak ise tibia frontal planına göre $60-70^{\circ}$ abduksiyondayken, beşinci alçı uygulanır. Ayak, bacağa göre aşırı düzeltilmiş konumdadır. Bu alçı yapılarak, ayak üç hafta alçıda tutulur. ${ }^{[5,8,9]}$

Kesinlikle pronasyon pozisyonu verilmemelidir.

\section{TENOTOMI}

Tenotomi, yapılacak olan son alçıdan (çoğunlukla beşinci alçı olur) önce, ekinusu düzelmemiş hastalara uygulanır. Zamanlaması kritik bir önem taşır. Tenotomiyi yapmadan önce, deformitenin ekinus dışındaki bileşenlerinin tamamen düzeldiğinden emin olmak gerekir. Bunu anlamanın bir yolu, kalkaneusun anterior kısmının talusun altından abduksiyona getirilebiliyor olduğunu gözlemlemektir. Kakaneusun ön kısmı abduksiyona getirilebiliyorsa, dorsifleksiyon esnasında talus kalkaneusun ön kısmı ve tibia arasında sıkışmayacak demektir. Abduksiyonun yeterli olduğunu kabul etmek için, aynı zamanda ayağın, tibia frontal düzlemine göre yaklaşık $60^{\circ}$ abduksiyona, kalkaneusun ise nötral veya hafif valgus pozisyonuna gelebildiğini gözlemlemek gerekir. Eğer abduksiyonun yeterli olmadığı görülürse, birkaç alçı daha yapmaktan kaçınılmamalıdır. ${ }^{[9]}$ 
Ayağın ekinus dışında bütün deformitelerinin düzeldiğine emin olunduktan sonra, tenotomi planlanır. Perkütan aşil tendon tenotomisi, genel anestezi veya sedasyon altında uygulanabileceği gibi, poliklinik şartlarında ve lokal anestezi ile de yapılabilir. Eğer lokal anestezi ile yapılacaksa, anestezik maddenin yüksek volümde infiltre edilmesi sonucu, tendonun hissedilmesinde zorluk yaşanabileceği akılda tutulmalıdır. ${ }^{[9]}$

Perkütan aşilotomi, Aşil tendonunun kalkaneusa yapışma yerinin yaklaşık $1 \mathrm{~cm}$ proksimalinden yapılır. Buna göre, cilt antiseptik bir çözelti ile temizlenip hazırlandıktan sonra, 11 ya da 15 numara bistüri veya oftalmik bistüri ucu ile tenotomi yapılır. Tenotomi yapılırken, kalkaneus kıkırdağına doğru kesmekten kaçınılmalıdır. ${ }^{[9]}$ Ayak bileği hafifçe dorsifleksiyona zorlanırken, tenotomi tamamlandığında bir 'pop' sesi hissedilir ve $10-15^{\circ}$ lik bir dorsifleksiyon açısı kazanılır. ${ }^{[5,9]}$ Günlük pratiğimizde biz, tenotomi işlemini genel anestezi altında ve ameliyathanede yapmayı tercih etmekteyiz.

Tenotomi tamamlanınca, son alçı daha önce tarif edildiği şekilde uygulanır ve üç hafta tutulur. Son alçının çıkarılacağı tarihte hazır olacak şekilde ortez siparişi verilir.

Perkütan tenotomi güvenli bir işlemdir. Tenotomi sonrası üçüncü haftada, hastaların yaklaşık \%70'inde klinik olarak, yaklaşık \%90'ında ise ultrasonografi (US) görüntülerinde tendonlarının intakt olduğu, sekizinci haftanın sonunda ise tenotomi yapılan bütün tendonların hem klinik hem de US kontrollerinde intakt olduğu görülmüştür. ${ }^{[16]}$

\section{ORTEZLEME}

Üç hafta tutulan son alçı açılır. Artık ayakta $30^{\circ}$ 'lik bir dorsifleksiyonun mümkün olduğu, düzelmenin tam, yara izinin çok az olduğu gözlenecektir. Böyle bir hasta artık ortezlemeye hazırdır. Ortez olarak Ponseti, Denis Browne ortezi kullanılmasını önermektedir. ${ }^{[9]}$

Ortez, ayak parmaklarının açıkta olduğu bir çift bağcıklı ayakkabı ve bu ayakkabıların ayarlanabilir bir açıyla bağlı olduğu demir bir çubuk parçasından oluşmaktadır. Bu demir çubuk, ayak bileğini yaklaşık $15^{\circ}$ dorsifleksiyonda tutacak şekilde, çocuktan uzak tarafta bir konveksiteye sahiptir. Demir çubuğun deformasyon göstermeyecek kadar sağlam olması ve çocuk büyüdükçe ayakkabıların bağlanma yerlerinin birbirinden uzaklaştırılabilmesi gerekir. Ayakkabılar demir çubuğa bağlandıklarında, her iki topuk arasındaki mesafe çocuğun omuzları arasındaki mesafe kadar olmalıdır. Ayakların birbirine yakın olması, çocukta huzursuzluğa neden olacaktır. Çocuk büyüdükçe bu mesafeyi değiştirmek gerekebilir. ${ }^{[9]}$
Eğer deformite tek taraflı ise, PEV'li taraf $75^{\circ}$, normal taraf $45^{\circ}$ dış rotasyonda tutulmalıdır. Bilateral tutulumlarda, her iki ayak da $70^{\circ}$ dış rotasyonda tutulacak şekilde demir çubuğa sabitlenmelidir.

Nadir olarak, ortez kullanılırken çocuğun topuğu aşırı valgusa ve tibiası da dış rotasyona dönebilir. Böyle bir durumda hekim, ayakkabıların dış rotasyonunu $70^{\circ}$ 'den $40^{\circ}$ 'ye indirmelidir. ${ }^{[9]}$

Son alçı çıkarılıp ortez takılınca, aileye uygulama öğretilmeli ve aile ilk günlerin biraz huzursuz geçeceği konusunda bilgilendirilmelidir. Bebek ve ailesi, 10 veya 14 gün sonra cihaz uygulamasının değerlendirilmesi ve varsa hataların erkenden düzeltilmesi için kontrole çağrılmalıdır. Bebek, yürüme refleksi nedeniyle, her iki ayağını birbirinin zıt yönünde hareket ettirecektir. Ancak, ortez nedeniyle her iki ayak birbiriyle bağımlı hareket edeceğinden, çocuk huzursuz olacaktır. Bu huzursuzluğu bir miktar azaltmak için, aile çocuğa, her iki ayağıyla birlikte tekme atmasını sağlayacak egzersizler yaptırılabilir. ${ }^{[9]}$

Çocuğun orteze alışıp her iki ayağılla tekme atmaya başlaması, bacak kaslarının da güçlenmesine yardımcı olacaktır. Ortezin bu dinamik etkisi, bütün bacağı sabitleyen uzun bacak ortezlerine göre bir üstünlük sağlar. ${ }^{[9]}$

Ortez kullanmak, nüksleri önler. Ortez kullanmayan serilerde nüks oranı yaklaşık \%80'lerde iken, ortez kullanımında bu oran \%6'lara düşmektedir.

Ortez, kullanma vakti geldiğinde, ilk altı ay gece ve gündüz devamlı olarak takılı kalmalıdır. Altı aydan sonra, üç yaşına gelene kadar, geceleri sürekli ve gündüzleri de 2-4 saat olmak üzere günde toplam 14-16 saat ortez kullanılmalıdır. Ortezi sonlandırma süresi, deformitenin başlangıç şiddetine göre değerlendirilebilir. Örneğin; şiddetli deformitelerde dört yıl, hafif deformitelerde iki yıl kullanabilir. Ancak, iki yıldan az kullanılması kesinlikle kabul edilmemelidir. ${ }^{[9]}$

Denis Browne ortezi yerine, sadece diz altından itibaren ayağı sabitleyen AFO (Ankle-Foot-Orthosis) benzeri cihazlar, rotasyonda yetersiz kalarak nükslere ve hareketi kısıtlayarak sertliğe neden olabilir. ${ }^{[2,9]}$

\section{NÜKSLERIN TEDAVISi}

Ponseti'ye göre nükslerin görülmesinin en sık nedeni, hastalığın ciddiyetinden ziyade, ortopedistlerin PEV'in kinematiğini ve nasıl düzeltilmesi gerektiğini anlayamamış olmalarıdır. ${ }^{[2]}$

Nüksleri tedavi etmenin ilk aşaması, bunları fark etmektir. Gelişebilecek nüksleri fark etmenin ilk adımı, düzenli aralıklarla hastayı takip muayenesine çağıııp kontrol etmektir. Ortez tedavisinin başlamasından sonra, ilk olarak 2. haftada, sonrasında ise 3 . ayda hasta kontrole çağrılır. Daha sonra, üç yaşına kadar 
eşit süre aralıklarıyla, yılda üç defa, sonraki bir yıl ise yılda iki defa kontrole çağrılarak, uyum problemleri ve nüksler değerlendirilir. ${ }^{[9]}$

Bebeklik döneminde ayak abduksiyon ve dorsifleksiyonundaki kayıplar ve metatarsus adduktusun tekrar görülmesi, nüks olarak değerlendirilmelidir. ${ }^{[9]}$

Oyun çocuklarında ise, yine dorsifleksiyon kaybı ve topuk varusu gelişmesi nüks olarak değerlendirilir. Ek olarak, tibialis anteriorun aşırı kasılması ve/veya peroneal kaslarda güçsüzlük nedeniyle, yürürken ayak önünün supinasyona gelmesi de nüks olarak değerlendirilir. Nüksler, ya ortezi düzenli kullanmamaktan ya da kas güçleri arasındaki dengesizlikten kaynaklanır. ${ }^{[9]}$

Nükslerle karşılaşıldığında, önceki manipülasyon ve alçı yönteminin aynısı uygulanarak, bir ila üç alçı yapılıp tekrar orteze geçilir. Bazen de, ortezin tekrar gece ve gündüz kullanılması redüksiyonu sağlayabilir. ${ }^{[6]}$

Ekinus deformitesi birkaç alçı ile düzeltilemezse, perkütan aşilotomi (bir yaşından küçükse) veya Aşil tendon uzatma (bir yaşından büyükse) ameliyatı gerekebilir. Böyle bir ameliyattan sonra, dört hafta ayak abduksiyonda ve diz $90^{\circ}$ fleksiyonda tutularak, uzun bacak alçısı yapılır. Sonrasında orteze devam edilir. ${ }^{[8]}$

Varusun nüksü daha sık görülür ve eğer çocuk iki yaşından küçükse tekrar alçılama, eğer iki yaşından büyükse ortez protokolünün daha sıkı uygulanması şeklinde durum çözüme kavuşturulur. Bazen mediyal gevşetme gerekebilir. ${ }^{[8]}$

Dinamik supinasyon geliştiğinde, yapısal bir deformite olup, olmadığı iyice değerlendirilmelidir. Eğer yapisal bir deformite yok ve durum sadece dinamik bir sorun ise, o zaman tibialis anterior tendon transferi gündeme gelebilir. Tibialis anterior tendon transferi yapılması gereken bir evrede operasyon geciktirilirse, ileride mediyal gevşetme yapmak gerekecektir. Bu durum ise, aşırı skar dokusu oluşmasına ve midtarsal eklemlerde sertlik gelişmesine neden olacaktır. ${ }^{[6]}$ Ancak, tibialis anterior tendon transferini yapabilmek için gereken operasyon, tendonun transfer edileceği lateral küneiformda çoğunlukla 30. ayda görülmeye başlanan kemikleşme merkezi görülene kadar ertelenmelidir. ${ }^{[2]}$

Normal şartlarda, bu ameliyat sonrasında ortez kullanılmasına gerek kalmaz. ${ }^{9]}$

Nüksler gelişse bile, hastalar, eğer Ponseti yöntemi ile tedavi edilmişlerse mediyal bağlar daha esnek olduğu için, operasyon yapılanlara göre daha kolay tedavi edilirler. ${ }^{[9]}$

İppolito ve arkadaşlarının, Ponseti yöntemi ile tedavi edilmiş, farklı yaşlardaki PEV'li hastaların kas hacimlerini manyetik rezonans görüntüleme ile değerlendirdikleri bir çalışmada; posteromediyal kas kompartmanında, kontrol gruplarına göre kas hacimleri arasında en fazla farkın, 4-6 yaşlarındaki hastalarda olduğunu tespit etmişlerdir. Ulaştıkları bu sonucun, Ponseti yöntemi ile tedavi edilmiş olsun veya olmasın, bu yaşlarda nükslerin daha fazla olmasıyla uyumlu olduğunu belirtmektedirler.

Ortez tedavisi bittikten sonra, hastaların yürürken giyecekleri ayakkabılarına taban yükseltmesi uygulanmasına gerek kalmaz. ${ }^{[8]}$

\section{KAYNAKLAR}

1. Alves C, Escalda C, Fernandes P, Tavares D, Neves MC. Ponseti method: does age at the beginning of treatment make a difference? Clin Orthop Relat Res 2009;467(5):1271-7. CrossRef

2. Ponseti IV. Common errors in the treatment of congenital clubfoot. Int Orthop 1997;21(2):137-41.

3. Wolff J. Gesetz der Transformation der Knochen. Berlin, Germany: Verlag von August Hirschwald; 1892.

4. Pirani, Shafique, Laura Zeznik, and David Hodges. Magnetic resonance imaging study of the congenital clubfoot treated with the Ponseti method. J Pediatr Orthop 2001;21(6):719-26.

5. Ponseti IV. Doğumsal Pes Ekinovarus - Tedavinin temelleri, 2. baskı. Türkçe çeviri editörü: Bursalı A. Ankara: Çocuk Ortopedisi Derneği; 2014.

6. Ponseti IV, Campos J. The classic: observations on pathogenesis and treatment of congenital clubfoot. 1972. Clin Orthop Relat Res 2009;467(5):1124-32. CrossRef

7. Ponseti IV. Treatment of congenital club foot. J Bone Joint Surg Am 1992;74(3):448-54.

8. Ponseti IV, Smoley EN. The classic: congenital club foot: the results of treatment. 1963. Clin Orthop Relat Res 2009;467(5):1133-45. CrossRef

9. Pirani S, Dietz F, Morcuende J, Mosca V, Herzenberg J, Weinstein S, Penny N, Steenbeek M. Pes Ekinovarus: Ponseti Yöntemi ile Tedavi. Çeviri editörü: Yalçın S. Global-HELP Yayınları; 2003.

10. Terrazas-Lafargue G, Morcuende JA. Effect of cast removal timing in the correction of Idipoathic clubfoot by the Ponseti method. lowa Orthop J 2007;27:24-7.

11. Elgohary HS, Abulsaad M. Traditional and accelerated Ponseti technique: a comparative study. Eur J Orthop Surg Traumatol 2015; 25(5):949-53. CrossRef

12. Morcuende JA, Abbasi D, Dolan LA, Ponseti IV. Results of an accelerated Ponseti protocol for clubfoot. J Pediatr Orthop 2005;25(5):623-6.

13. Harnett P, Freeman R, Harrison WJ, Brown LC, Beckles V. An accelerated Ponseti versus the standard Ponseti method: a prospective randomised controlled trial. J Bone Joint Surg Br 2011;93(3):404-8. CrossRef

14. Xu RJ. A modified Ponseti method for the treatment of idiopathic clubfoot: a preliminary report. J Pediatr Orthop 2011;31(3):317-9. CrossRef

15. Zhao D, Li H, Zhao L, Liu J, Wu Z, Jin F. Results of clubfoot management using the Ponseti method: do the details matter? A systematic review. Clin Orthop Relat Res 2014;472(4):1329-36. CrossRef

16. BarkerSL, Lavy CB. Correlation of clinical and ultrasonographic findings after Achilles tenotomy in idiopathic club foot. J Bone Joint Surg Br 2006;88(3):377-9. 